\title{
New APProach OF Measuring Toxic GaSeS CONCENTRATIONS: APPLICATION EXAMPLES
}

\author{
Dzevad Bibic, Boran Pikula, Adnan Masic \& Faruk Razic
}
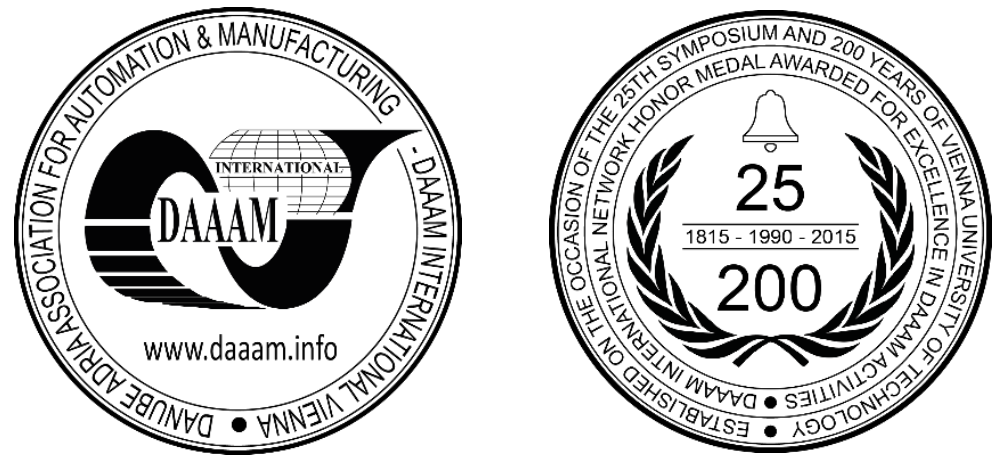

This Publication has to be referred as: Bibic, D[zevad]; Pikula, B[oran]; Masic, A[dnan] \& Razic, F[aruk] (2018). New Approach of Measuring Toxic Gases Concentrations: Application Examples, Proceedings of the 29th DAAAM International Symposium, pp.0876-0881, B. Katalinic (Ed.), Published by DAAAM International, ISBN 978-3-90273420-4, ISSN 1726-9679, Vienna, Austria

DOI: $10.2507 / 29$ th.daaam.proceedings.126

\begin{abstract}
Low-cost electrochemical sensors and in-house developed data acquisition system are used in two experiments, which reflect real-life scenarios of air pollution. Primary aim of this research is evaluation of the new approach for measuring the concentrations of toxic gases in realistic, everyday situations. These experiments include: continuous diurnal monitoring of toxic gases concentrations in public underground garage and mobile measurements of toxic gases concentrations on urban streets in real time using the motorbike as sensors' carrier.
\end{abstract}

Keywords: air pollution; electrochemical sensor; diurnal profile; mobile measurements

\section{Introduction}

According to the World Health Organization (WHO), 4.2 million people die every year due to the ambient air pollution and 3.8 million more as a result of household exposure to smoke from dirty cookstoves and fuels, while $91 \%$ of the world's population lives in places where air quality exceeds WHO guideline limits [1]. Furthermore, according to data available in [2], about 400,000 people die only in Europe although air quality standards have been defined 20 years ago. An important step towards the solution of the problem of air pollution is monitoring of the concentrations of toxic gases in the air. However, vast majority of the population affected by the excessive air pollution live in developing countries [3]. Hence, affordable and reliable methods for monitoring of toxic gases are urgently needed. A very promising approach is to use commodity electrochemical sensors [4], recently developed by Alphasense Ltd (UK).

The basic principles of the electrochemical sensors of Alphasense Ltd (UK) are presented in [5]. Having in mind that the low-cost sensors have small dimensions, a compact housing is designed where several of these sensors are located. This enables measurement of some of the characteristic emissions of polluting components in the air. Besides the measurements at various stationary locations (road intersections, parks, underground garages, workshops, factories, etc.), it is possible to make measurements of air pollutants during vehicle motion (car, motorcycle, bicycle, etc.) in realistic traffic conditions. The authors of this paper have already performed measurements of PM1, PM2.5 and PM10 concentrations in the air during drive of the vehicle on urban traffic roads, as it shown in the [6]. 
Therefore, this paper aims to present the possibilities of using the electrochemical sensors under different conditions, such as continuous diurnal monitoring of toxic gases concentrations in public underground garage and mobile measurements of toxic gases concentrations on urban streets in real time.

\section{Examples of application in realistic conditions}

As mentioned above, the several different Alphasense sensors are located in the compact housing of their own air quality measurement device: $\mathrm{SO}_{2}-\mathrm{B} 4$ range sensor (0-100) ppm, sensor CO-A4 range (0-500) ppm, sensor NO-A4 range (0-20) ppm, $\mathrm{NO}_{2}-\mathrm{A} 4$ range sensor (0-20) ppm and $\mathrm{O}_{\mathrm{X}}-\mathrm{A} 4$ sensor, range $(0-20) \mathrm{ppm}$. In order to demonstrate the application possibilities, two characteristic examples of air quality measurements were selected using the following sensors:

a) Enclosed within a single shopping centre with underground garage, at the location of the vehicle's technical inspection station and

b) In the realistic conditions of motorcycle movement with all crowds and traffic flows in the urban environment.

\subsection{Stationary measurement of air quality in an underground garage}

The stationary measurement of air quality in the underground closed garage was carried out at one shopping centre at the location of the vehicle's technical inspection station. The same technical inspection station, along with the car wash, is located at the very end of the building of the shopping centre where there is no large traffic of the vehicles. The working hours of the vehicle's technical inspection station are from 08.00 to 17.00 , which means that the station is closed from 17.00 to 08.00 hours by two sliding doors. Within the same location of the technical inspection station of the vehicle there is also a ventilation system that plays a significant role in the non-working hours as will be seen on the results shown below. The view on the vehicle technical inspection station, as well as the position of the device with the specified Alphasense sensors, are shown in the Figure 1.
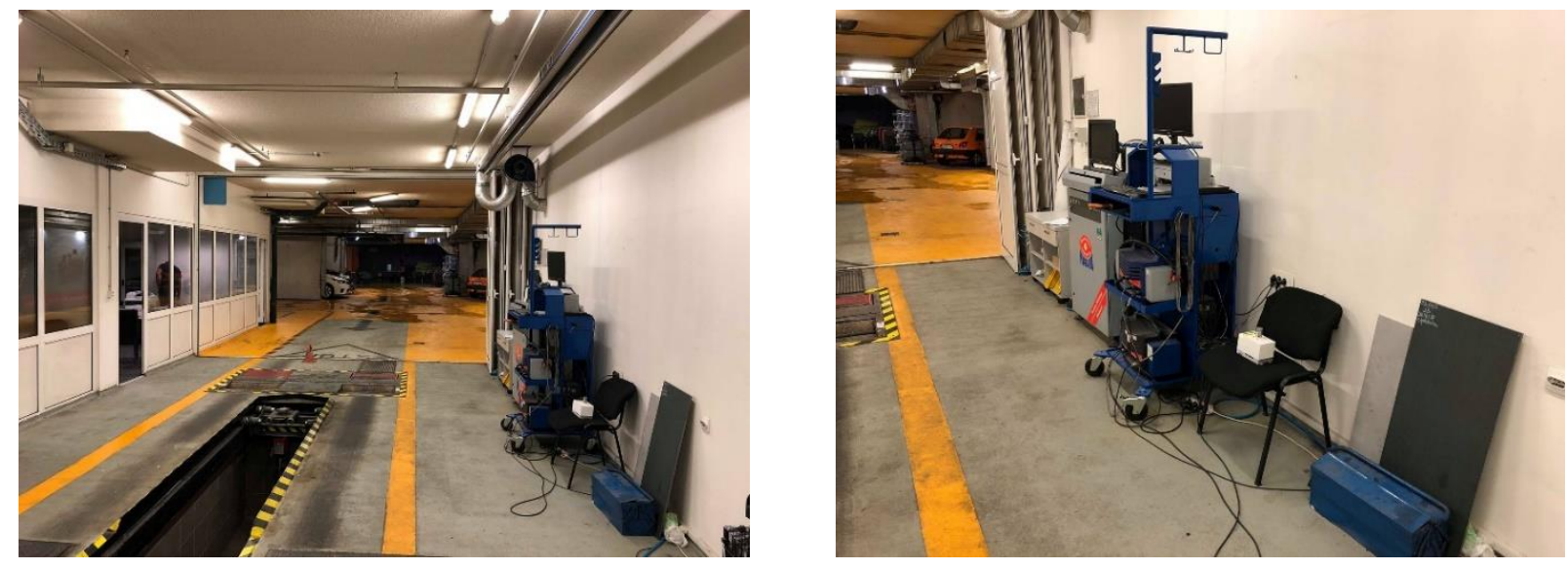

Fig. 1. The vehicle technical inspection station in the underground garage with a device for air quality measurements

The Air Quality Measurement Device with the specified sensors by Alphasense is positioned at the middle of the vehicle's technical inspection station, next to the MAHA Exhaust Gas Analyser. The device was set on September 18, 2018 afternoon in order to reach the working temperature and be ready for measurement at the beginning of the next working day. The official measurements were performed on September 19 and 20, 2018, which resulted obtaining of very interesting results.

Due to the scope of the results, only some characteristic results relating to the minute and hourly averages of certain emissions will be shown in this paper. The Figure 2 shows the minute averages of $\mathrm{CO}$ and $\mathrm{NO}_{2}$ emissions, while the hourly average for $\mathrm{NO}_{2}$ emission is given in the Figure 3 in order to compare it with the limit values prescribed by the regulation in Bosnia and Herzegovina [7]. If we compare the minute and hour averages shown in the Figure 2 and the Figure 3, it can be concluded that they generally have very similar trends. Only minute averages show significant current results increasing due to a very short period of a vehicle being tested at a technical inspection station or on a moving vehicle near the technical inspection station. It can be seen that the minute average values of current $\mathrm{NO}_{2}$ emissions are almost 10 times higher than the $\mathrm{NO}_{2}$ hourly emission.

Based on the results shown in the Figure 3, it can be seen that, due to the non-working hours during night and the insulated closed space of the vehicle's technical inspection, as well as the operation of the ventilation system, there are the significant reduction in the hourly average of the $\mathrm{NO}_{2}$ emission. During the working hour and the openness of the space in which a motor vehicle inspection is performed, as well as the presence of vehicles near to the station, the hourly averages of the $\mathrm{NO}_{2}$ emissions are increased. It leads to the fact that after 12 hours of workday, this emission exceeds the permitted hourly limit defined [7]. 


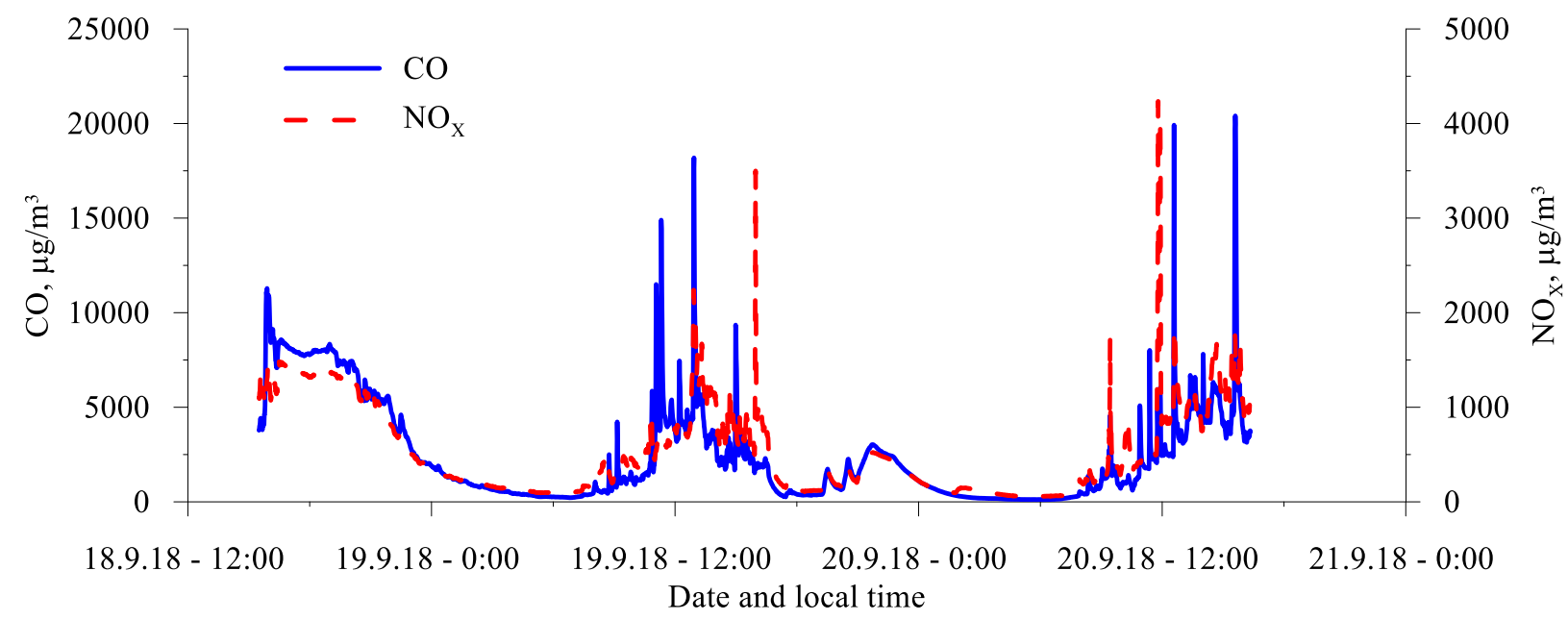

Fig. 2. Minute averages of $\mathrm{CO}$ and $\mathrm{NO}_{2}$ emissions during two-day measurement in the garage area of the shopping centre

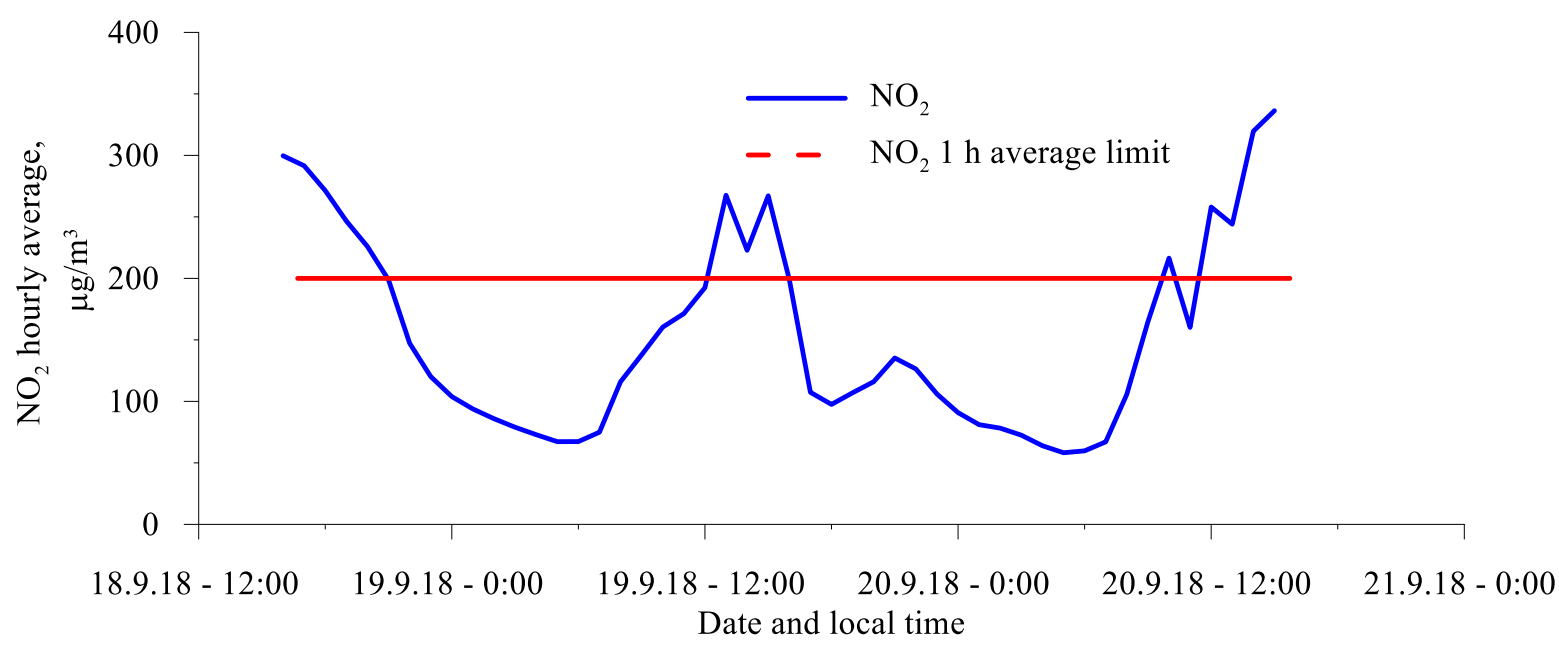

Fig. 3. $\mathrm{NO}_{2}$ emission hourly average during two-day measurement in the garage area of the shopping centre

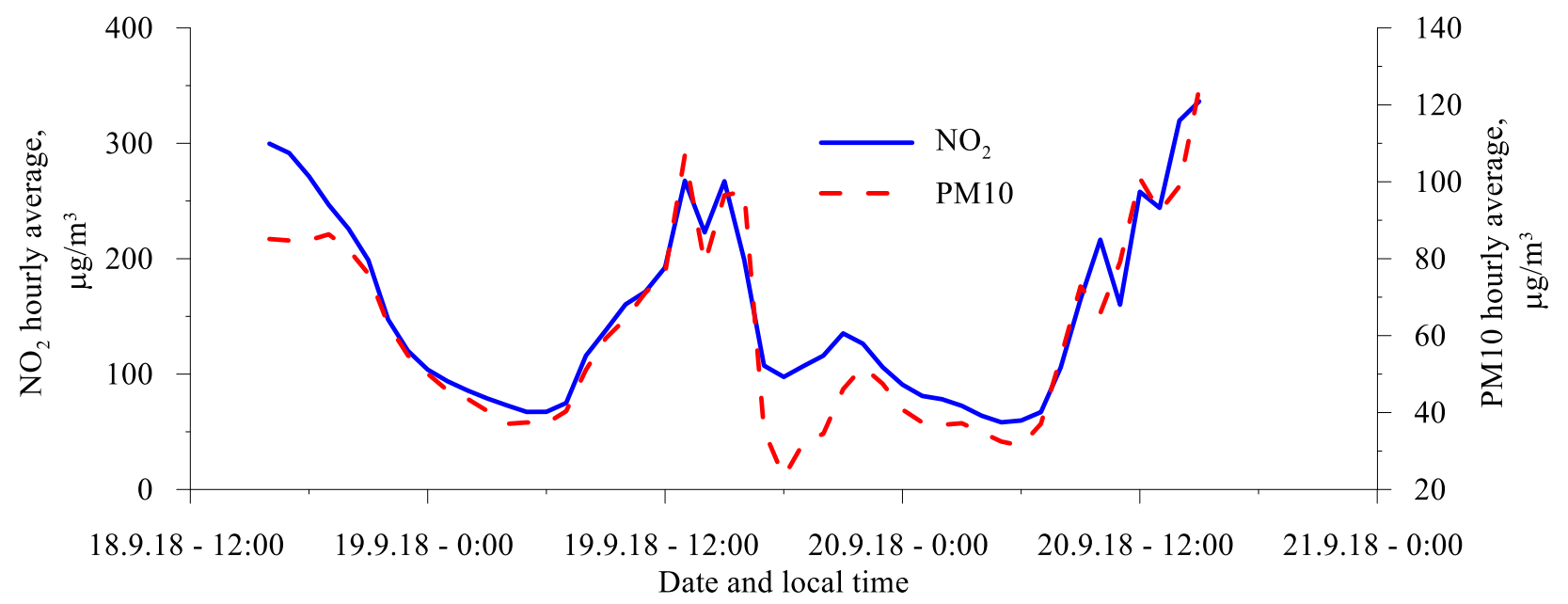

Fig. 4. Hourly averages of $\mathrm{NO}_{2}$ emission and PM10 particle emissions during two-day measurement in the underground garage area of the shopping centre 
Since the device is simultaneously equipped with PM particle sensors, it is easy to point to the connection between $\mathrm{NO}_{2}$ and particulate emission (PM10). The characteristic $\mathrm{NO}_{2}$ emission and particles in the form of hourly averages are shown in the Figure 4, which shows a very good consistency. Within the previous example, only one device was used and accordingly it was present to only one micro location. By using and installing multiple devices of this type on connected micro locations, it is possible to establish a complete map of an open or closed area [4]. Benefits from such collected results data can be multiple. On the one hand, it would be possible to identify the most vulnerable zones, on the other hand, to establish the source of such an air pollution status.

\subsection{Mobile Air Quality Measurement in Urban Traffic Areas}

To capture live pollution data from urban traffic it's necessary to attach the measuring device to a vehicle that's capable to follow the traffic flow, and simultaneously offers an adequate mounting space. In previous measurements, to avoid pollutant data collecting from the device carrier an electrical vehicle was used [8]. In the presented scenario of vehicle motion this vehicle would not be a good choice because of its limited range, dimensions and manoeuvrability. That for mobile air quality measurement on urban traffic ways was carried out during the movement of the motorcycle by BMW, type C650 Sport. This motorcycle was chosen due to the fact that it is a "maxi scooter" and it is suitable for placing a bag in the free space between the steering handlebar and the driver's seat, where the mentioned device has been placed. This reduces the potential impact of the wind in the form of turbulent air flow to the device itself. Setting up the measuring device for performing mobile air quality measurements is shown in the Figure 5.

In the Figure 5, the Racelogic VBox Sport device is also located and set up, which allows to record the speed of a motorcycle by using a GPS technology with a $20 \mathrm{~Hz}$ operating frequency. While the Racelogic VBox Sport has its own power supply, the power supply of the air quality measurement device is done with a battery and a USB connector.
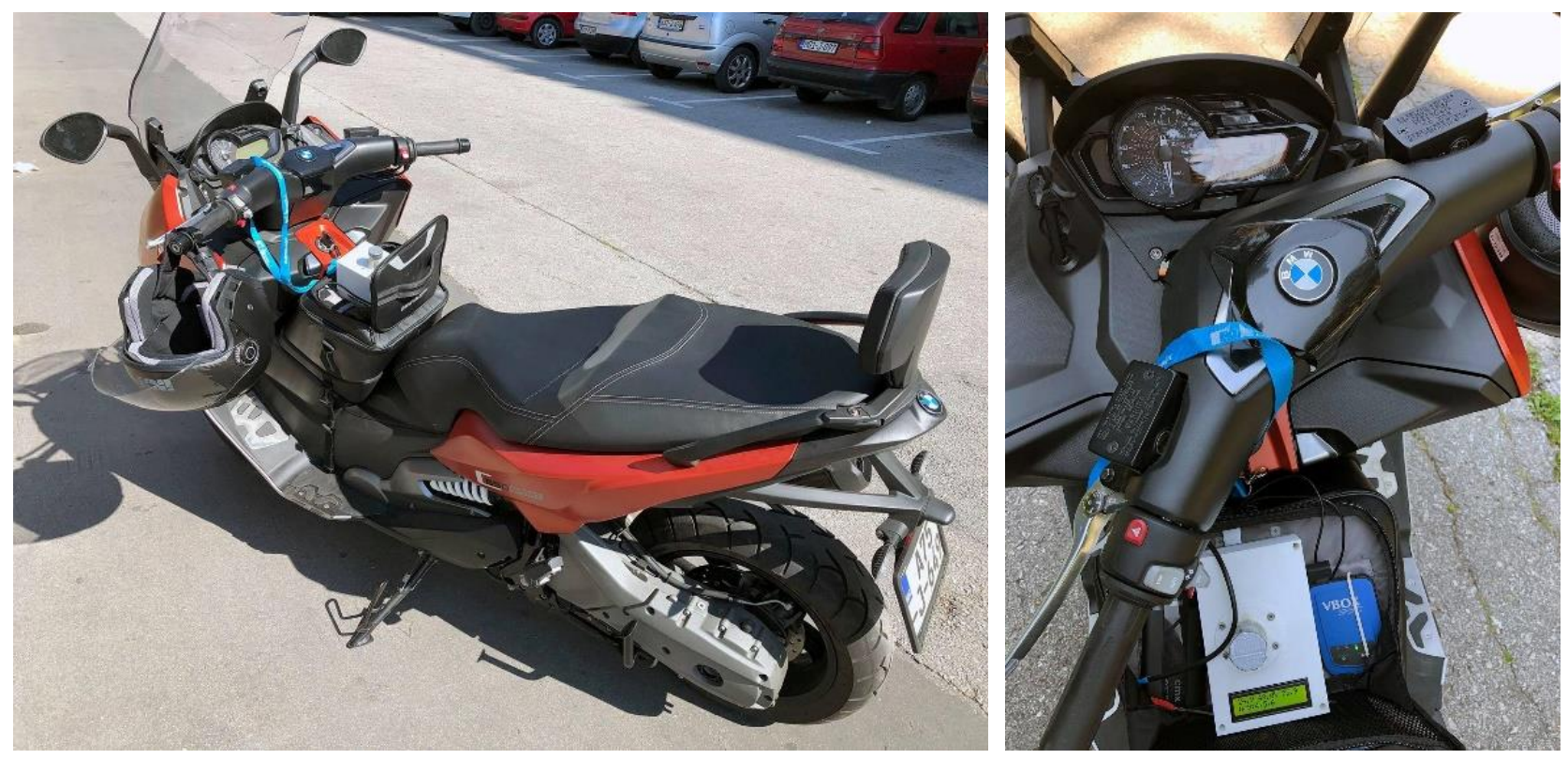

Fig. 5. The air quality measuring device mounted on a motorcycle for mobile measurements

Driving a motorcycle with the task of measuring the air quality was done in the early evening hours of a sunny day at the end of August 2018 for more than 2 hours. At this point, with an average speed of less than $30 \mathrm{~km} / \mathrm{h}$, it was achieved about $60 \mathrm{~km}$ a long trip to go through the typical roads in the urban environment. This involved driving the main road in both directions, with a larger number of vehicles, of course at a higher speed. In the same time, driving through the transversal streets lower speeds are achieved. It is very important to notice, the air temperature during the movement on the mentioned section was (21-24) ${ }^{\circ} \mathrm{C}$, thus meeting Alphasense's recommendations for using the aforementioned sensors.

The $\mathrm{CO}$ and $\mathrm{NO}_{2}$ emissions results, spatially within the urban environment in which the motion of the motorcycle is achieved, are shown in the Figures 6 and 7. The Figure 6 shows the CO emission in the range $(225-1000) \mu \mathrm{g} / \mathrm{m}^{3} \mathrm{achieved}$ when the motorcycle is moving through the urban environment. By analysing the results shown in the Figure 6 , it can be concluded that the largest $\mathrm{CO}$ emissions are measured at the main road where the largest number of vehicles is located, moving at a relatively high speed. In the urban environment where secondary roads are located, which characterize the movement of a smaller number of vehicles at a relatively lower speed, there is a lower level of CO emission. A similar conclusion can also be made in the case of $\mathrm{NO}_{2}$ emission in the range (50-200) $\mu \mathrm{g} / \mathrm{m}^{3}$ as shown in the Figure 7. 


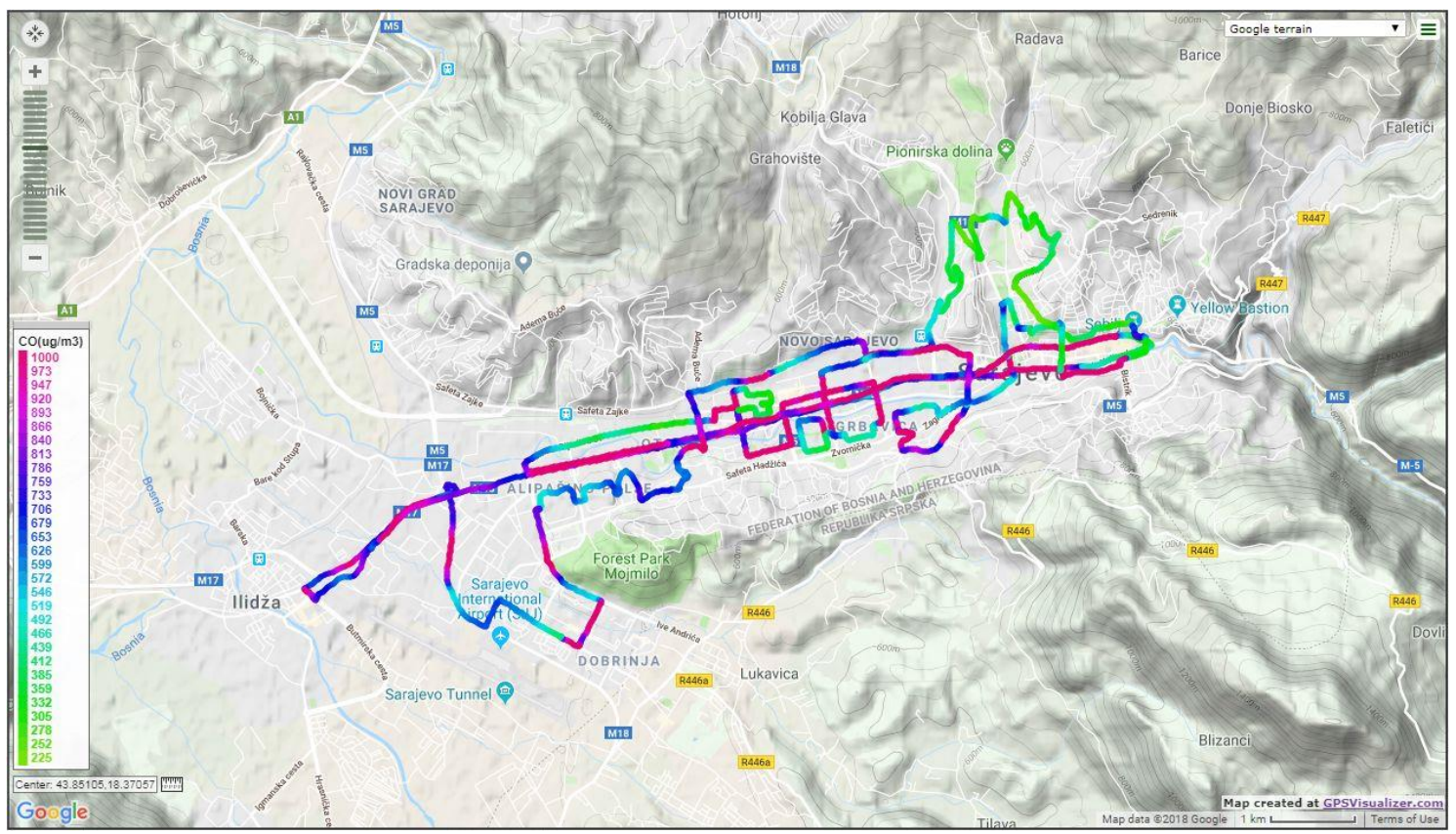

Fig. 6. $\mathrm{CO}$ emission during mobile metering in the urban environment

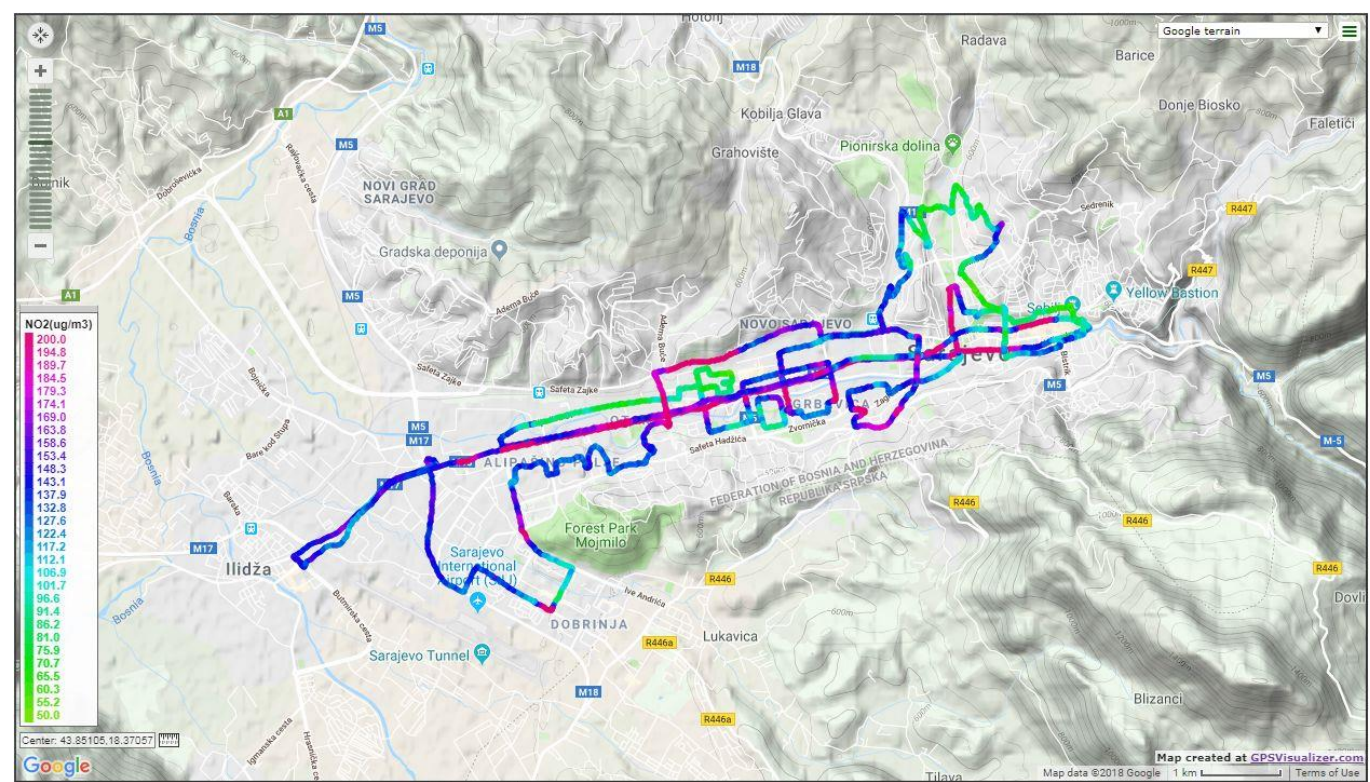

Fig. 7. $\mathrm{NO}_{2}$ emission during mobile metering in the urban environment

Through these two different examples (stationary and mobile case application of the device) it has been shown that the optimal design and functionality of the device with all the associated sensors can be made by each user, so in our case a choice of electrochemical sensors for measuring emissions of polluting components and sensors for particle measurement were done.

\section{Conclusion}

For the purpose of stationary and mobile metering of air pollutants, the own designed device was developed which, by using Alphasense's low-cost sensor, allows air quality measurements. This work encompasses two characteristic measurements: the space in a closed underground garage, in addition to the vehicle's technical inspection station, and mobile metering in the urban environment thanks to the motion of the motorcycle. Both examples have shown the capability and performance of these sensors to define air quality. In this way, the possibilities of defining the air quality at each location from school classrooms, workplaces in factories, offices, restaurants, underground garages etc. are opened. Having in mind the great potential and flexibility of these sensors, and expecting their further development, every single person or firm can design own device with optimum application possibilities. 


\section{References}

[1] http://www.who.int/airpollution/en/, (2018). World Health Organization, Accessed on: 2018-09-23

[2] https://www.weforum.org/agenda/2018/09/europe-s-dirty-air-kills-400-000-people-every-year/

[3] Kumar, R. (2018). Five steps to improve air-quality forecasts. Nature, 561 (2018) 27-29

[4] Mead, M. I.; Popoola, O. A. M.; Stewart, G. B.; Landshoff, P.; Calleja, M.; Hayes, M.; Baldovi, J. J.; McLeod M. W.; Hodgson T. F.; Dicks J.; Lewis A.; Cohen J.; Baron R.; Saffell J. R. \& Jones, R. L. (2013). The use of electrochemical sensors for monitoring urban air quality in low-cost, high-density networks. Atmospheric Environment, 70 (2013) 186-203

[5] Masic, A.; Bibic, Dz.; Pikula, B.; Razic, F.: New Approach of Measuring Toxic Gases Concentrations: Principle of Operation; (2018) Proceedings of the 29th DAAAM International Symposium pp.xxx-xxx, B. Katalinic (Ed.), Published by DAAAM International, ISBN 978-3-902734-11-2, ISSN 1726-9679, Vienna, Austria, DOI: $10.2507 / 29$ th.daaam.proceedings.Xxx, in press

[6] Masic, A.; Pikula, B. \& Bibic, Dz. (2017). Mobile Measurements of Particulate Matter Concentrations in Urban Area, Proceedings of the 28th DAAAM International Symposium, pp.0452-0456, B. Katalinic (Ed.), Published by DAAAM International, ISBN 978-3-902734-11-2, ISSN 1726-9679, Vienna, Austria, DOI: 10.2507/28th.daaam.proceedings.063

[7] Pravilnik o nacinu vrsenja monitoringa kvaliteta zraka i definiranju vrsta zagadjujucih materija, granicnih vrijednosti i drugih standarda kvaliteta zraka, (2012) Sluzbene novine Federacije BiH br. 1/12

[8] Masic, A.; Pikula, B. \& Bibic, Dz. (2017) Dynamic Characteristics of the Electrical Vehicle, Proceedings of the 28th DAAAM International Symposium, pp.0446-0451, B. Katalinic (Ed.), Published by DAAAM International, ISBN 978-3-902734-11-2, ISSN 1726-9679, Vienna, Austria, DOI: 10.2507/28th.daaam.proceedings.062 